\title{
ON A TOTAL VERSION OF 1-2-3 CONJECTURE ${ }^{1}$
}

\author{
Olivier Baudon $^{1}$, Hervé Hocquard $^{1}$ \\ Antoni MarczyK ${ }^{2}$, Monika Pilśniak ${ }^{2}$ \\ JAKuB PRZYBYŁo ${ }^{2}$ AND MARIUSz WoŹNIAK ${ }^{2}$ \\ ${ }^{1}$ Université de Bordeaux and CNRS \\ LaBRI, UMR 5800 \\ F-33400 Talence, France \\ ${ }^{2}$ Faculty Applied Mathematics \\ AGH University of Science and Technology \\ Al. Mickiewicza 30,30-059 Kraków, Poland \\ e-mail: baudon@labri.fr \\ hocquard@labri.fr \\ marczyk@agh.edu.pl \\ pilsniak@agh.edu.p \\ jakubprz@agh.edu.pl \\ mwozniak@agh.edu.pl
}

\begin{abstract}
A total $k$-coloring of a graph $G$ is a coloring of vertices and edges of $G$ using colors of the set $\{1, \ldots, k\}$. These colors can be used to distinguish adjacent vertices of $G$. There are many possibilities of such a distinction. In this paper, we focus on the one by the full sum of colors of a vertex, i.e., the sum of the color of the vertex, the colors on its incident edges and the colors on its adjacent vertices.

This way of distinguishing vertices has similar properties to the method when we only use incident edge colors and to the corresponding 1-2-3 Conjecture.

Keywords: neighbor sum distinguishing total coloring, general edge coloring, total coloring, neighbor-distinguishing index, neighbor full sum distinguishing total $k$-coloring.
\end{abstract}

2010 Mathematics Subject Classification: 05C15.

\footnotetext{
${ }^{1}$ We acknowledge the support by CNRS-PICS Project no. 6367 "GraphPar". The fifth author was supported by the National Science Centre, Poland, grant no. 2014/13/B/ST1/01855. The third, fourth, fifth and sixth authors were also partly supported by the Polish Ministry of Science and Higher Education. The sixth author was supported by the National Science Centre, Poland, grant no. DEC-2013/09/B/ST1/01772.
} 


\section{REFERENCES}

[1] M. Axenovich, J. Harant, J. Przybyło, R. Soták and M. Voigt, A note on adjacent vertex distinguishing colorings number of graphs, Discrete Appl. Math. 205 (2016) $1-7$. doi:10.1016/j.dam.2015.12.005

[2] J.A. Bondy and U.S.R. Murty, Graph Theory with Applications (Macmillan, London, 1976).

[3] G. Chartrand, M.S. Jacobson, J. Lehel, O.R. Oellermann, S. Ruiz and F. Saba, Irregular networks, Congr. Numer. 64 (1988) 197-210.

[4] S. Czerwiński, J. Grytczuk and W. Żelazny, Lucky labelings of graphs, Inform. Process. Lett. 109 (2009) 1078-1081. doi:10.1016/j.ipl.2009.05.011

[5] A. Davoodi and B. Omoomi, On the 1-2-3-conjecture, Discrete Math. Theor. Comput. Sci. 17 (2015) 67-78.

[6] R.J. Faudree, M.S. Jacobson, J. Lehel and R.H. Schelp, Irregular networks, regular graphs and integer matrices with distinct row column sums, Discrete Math. 76 (1989) 223-240. doi:10.1016/0012-365X(89)90321-X

[7] E. Flandrin, H. Li, A. Marczyk, J-F. Saclé and M. Woźniak, A note on neighbor expanded sum distinguishing index, Discuss. Math. Graph Theory 37 (2017) 29-37. doi:10.7151/dmgt.1909

[8] M. Kalkowski, A note on 1,2-conjecture, Ph.D. Thesis (UAM Poznań, 2009).

[9] M. Kalkowski, M. Karoński and F. Pfender, Vertex-coloring edge weightings: Towards the 1-2-3-conjecture, J. Combin. Theory Ser. B 100 (2010) 347-349. doi:10.1016/j.jctb.2009.06.002

[10] M. Karoński, T. Łuczak and A. Thomason, Edge weights and vertex colours, J. Combin. Theory Ser. B 91(2004) 151-157.

doi:10.1016/j.jctb.2003.12.001

[11] M. Khatirinejad, R. Naserasr, M. Newman, B. Seamone and B. Stevens, Vertexcolouring edge weightings with two edge weights, Discrete Math. Theor. Comput. Sci. 14 (2012) 1-20. doi:10.7748/en.20.1.14.s6

[12] J. Przybyło and M. Woźniak, On a 1,2 conjecture, Discrete Math. Theor. Comput. Sci. 12 (2010) 101-108.

[13] B. Seamone, The 1-2-3 conjecture and related problems: a survey, Technical Report (2012). http://arxiv.org/abs/1211.5122

[14] C. Thomassen, Y. Wu and C.-Q. Zhang, The 3-flow conjecture, factors modulo $k$, and the 1-2-3-conjecture, J. Combin. Theory Ser. B 121 (2016) 308-325. doi:10.1016/j.jctb.2016.06.010 
Received 12 July 2018

Revised 23 April 2019

Accepted 23 April 2019 